\title{
The positive impacts of landscape fragmentation on the diversification of agricultural production in Zhejiang Province, China
}

Article

Accepted Version

Creative Commons: Attribution-Noncommercial-No Derivative Works 4.0

Qiu, L., Zhu, J., Pan, Y., Wu, S., Dang, Y., Xu, B. and Yang, H. (2020) The positive impacts of landscape fragmentation on the diversification of agricultural production in Zhejiang Province, China. Journal of Cleaner Production, 251. 119722. ISSN 0959-6526 doi: https://doi.org/10.1016/j.jclepro.2019.119722 Available at https://centaur.reading.ac.uk/88505/

It is advisable to refer to the publisher's version if you intend to cite from the work. See Guidance on citing.

To link to this article DOI: http://dx.doi.org/10.1016/j.jclepro.2019.119722

Publisher: Elsevier

All outputs in CentAUR are protected by Intellectual Property Rights law, including copyright law. Copyright and IPR is retained by the creators or other copyright holders. Terms and conditions for use of this material are defined in the End User Agreement. 


\section{CentAUR}

Central Archive at the University of Reading

Reading's research outputs online 
1 The positive impacts of landscape fragmentation on 2 the diversification of agricultural production in 3 Zhejiang Province, China

4

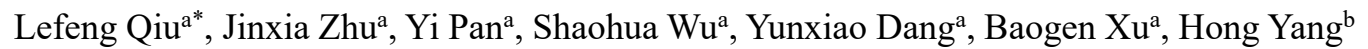

${ }^{a}$ Institute of Land and Urban-rural Development, Zhejiang University of Finance and Economics, Hangzhou, 310018, China

${ }^{\text {b} D e p a r t m e n t ~ o f ~ G e o g r a p h y ~ a n d ~ E n v i r o n m e n t a l ~ S c i e n c e, ~ U n i v e r s i t y ~ o f ~ R e a d i n g, ~ R e a d i n g, ~ R G 6 ~ 6 A B, ~}$ UK

*Corresponding author.

\section{Abstract}

Agricultural land fragmentation has an important impact on ecosystem services, especially food production. However, the relationship between land fragmentation and production diversification remains controversial and requires further analysis. This study characterized the dynamics of land fragmentation and production diversification in Zhejiang Province, China, from 1995 to 2015 using remote sensing, landscape metrics, and a diversification assessment approach. The results showed that Zhejiang Province experienced increasing fragmentation of agricultural landscapes and profound diversification of agricultural production. Fragmentation had a significant negative effect on grain crop production, but it had a significant positive effect on production diversification. These findings showed that fragmentation is an important driver of the diversification of agriculture and contributes to increased dietary diversity in local households. Therefore, we believe that when addressing land fragmentation issues, both the positive and negative impacts of fragmentation in different local conditions and circumstances should be taken into account. Our findings will provide scientific support for land consolidation management and agricultural land resource protection.

Keywords: Land fragmentation; Production diversity; Land consolidation; Sustainability; Agricultural development; Zhejiang 


\section{Introduction}

Agricultural land fragmentation caused by land use change and urbanization may have serious impacts on ecosystem services, especially agricultural production (Lee et al., 2015; Costanza et al., 2017). Fragmentation has negative impacts, such as a significant increase in the cost of agricultural production (Liu et al., 2014; Lu et al., 2019) and a decrease in the technical and scale efficiency of agricultural production (Tan et al., 2010). However, there are also ongoing debates about the benefits of fragmentation to farmers under varying conditions. The positive effect is mainly reflected in the enrichment of the internal planting structure of agriculture (Ntihinyurwa et al., 2019), the increase in the utilization of labour resources (Tan et al., 2008), and the diversification of risks in relation to agricultural markets, thereby increasing farmers' income (Lu et al., 2018). In this context, characterizing the relationship between landscape pattern changes and agricultural production has become a critical step for evaluating the comprehensive effect of fragmentation and developing subsequent land management policies.

China provides a typical case study for this effort. The Household Responsibility System (HRS) implemented in China contributed to rapid rural development by increasing farmers' incomes and eliminating rural poverty. However, its implementation also led to each household separately holding numerous small, scattered plots of lands (Lu et al., 2018). In 2016, China had only 0.09 ha of cultivated land per capita, far below the global average of 0.20 ha per capita (World Bank, 2016). Furthermore, accelerating urbanization results in the physical fragmentation of agricultural land. The disorderly establishment of a large number of urban construction sites led to scattered, isolated, and irregular agricultural landscapes (Su et al., 2012; Lai et al., 2016). Zhang et al. (1997) found that fragmentation wastes $5 \%$ of the effective area for farming in China and reduces land productivity by $15 \%$.

At present, there are two main branches of research on the phenomenon of land fragmentation: land ownership fragmentation and physical land fragmentation (Ntihinyurwa et al., 2019). Previous studies frequently focused on the basic plots operated by farmers, assessing the ownership of plots, the size and number of plots, the distance between plots, and the spatial distribution of plots from a socioeconomic perspective (Wan and Cheng, 2001; Tan et al., 2010; Jia and Petrick, 2014; Lu et al., 2019). However, from the perspective of landscape ecology, the composition and configuration of different landscape patches will significantly affect ecosystem services (Coleman et al., 2017; Walz and Syrbe, 2018). The spatial heterogeneity of the landscape characteristics of agricultural land in relation to agricultural 
production should receive more attention (Lee and Huang, 2018). The relationship between landscape fragmentation (LF) and agricultural production has yet to be studied. Since it is difficult to quantify land fragmentation, the majority of studies use the number of plots owned by farmers or their average size to measure fragmentation (Latruffe and Piet, 2014; Sibhatu et al., 2015), or they combine relevant information to construct comprehensive indicators for reflecting fragmentation, such as the Januszewski index or the Simpson index (Kawasaki, 2010; Ciaian et al., 2018). However, these indices ignore critical spatial variables, such as the spatial isolation of farm fields and the shape of parcels. In addition, these indices are commonly used for plot-level or farm-level studies and are difficult to apply in regional fragmentation studies involving a larger spatial scale due to costly on-site investigations. Although the information obtained from plot-scale research is more accurate, the observation of fragmentation patterns throughout study areas in landscape-scale studies is more comprehensive (Mekki et al., 2018). Thus, it has been proposed that the evaluation and application of landscape metrics is an efficient alternative for quantifying fragmentation at the regional level (Cheng et al., 2015; Rosa et al., 2017; Lee and Huang, 2018).

An important aspect of the effect of land fragmentation on agricultural production is the diversification in the yields of different crops. Empirical literature mostly focuses on different factors that influence farmers' diversification choices in agricultural production, such as farm household characteristics, capital investments, crop price changes, technological updates, geographical location, soil conditions, natural climate, and local agricultural policies (Sichoongwe et al., 2014; Loison, 2015; McCord et al., 2015; Makate et al., 2016). Another important consideration is that the fragmentation of regional agricultural land may potentially increase the diversity of agricultural products. Few studies have revealed the relationship between land fragmentation and agricultural production diversification (APD), despite a considerable number of studies analysing the determinants of APD (Ciaian et al., 2018). Moreover, the few available studies find mixed evidence. For instance, Ciaian et al. (2018) and Mekki et al. (2018) confirmed a positive effect of land fragmentation on production diversification at the level of household farms in Albania and at the landscape level in Tunisia, but Sichoongwe et al. (2014) found a statistically nonsignificant impact of land fragmentation on diversification at the level of smallholders in Zambia. It is imperative to find more concrete evidence for specific areas at a more macro scale (Sichoongwe et al., 2014). 
To fill the knowledge gap, this study examines the impact of LF on APD using Zhejiang Province, China, as a case study. A comprehensive approach combining remote sensing, landscape metrics and an APD assessment method was developed to address the following three questions: (1) How did agricultural landscape patterns change in response to urbanization in Zhejiang Province from 1995 to 2015? (2) How did agricultural production change in the context of rapid economic development? (3) What is the relationship between land fragmentation and production diversification?

\section{Materials and methods}

\subsection{Study area}

Zhejiang Province $\left(118^{\circ} 1^{\prime}-122^{\circ} 26^{\prime} \mathrm{E}, 27^{\circ} 9^{\prime}-31^{\circ} 11^{\prime} \mathrm{N}\right)$ is located in the southern part of the Yangtze River Delta in China (Fig. 1). Zhejiang covers an area of approximately $105,500 \mathrm{~km}^{2}$. The landscape is characterized by mountainous topography. Hilly mountains account for $74.63 \%$ of the total area, plains account for $20.32 \%$, and water bodies account for $20.32 \%$. With a population of 56.57 million in 2017 , Zhejiang Province is one of the provinces with the smallest per-capita cultivated land area in China (The People's Government of Zhejiang Province, 2019). Since the 1980s, the commercialization of agriculture in Zhejiang Province has developed rapidly, changing from single grain production to the cultivation of higher-profit cash crops, such as tea, fruits, vegetables, and oil plants (Su et al., 2014). In the context of rapid economic development and urbanization, Zhejiang Province is one of the richest and most developed provinces in China (Zhao et al., 2019). The widespread transition from agricultural land to construction land has intensified the fragmentation, irregularity, and isolation of agricultural patches across the region (You, 2017). As a result, agricultural production is increasingly affected by land fragmentation. The Zhejiang Provincial Government has proposed ecologically sustainable agriculture as the development target of Zhejiang's future agriculture (Zhejiang Agricultural Department, 2016). However, regarding the need to control land fragmentation, no comprehensive study on the relationship between agricultural development and land fragmentation has previously been conducted. 


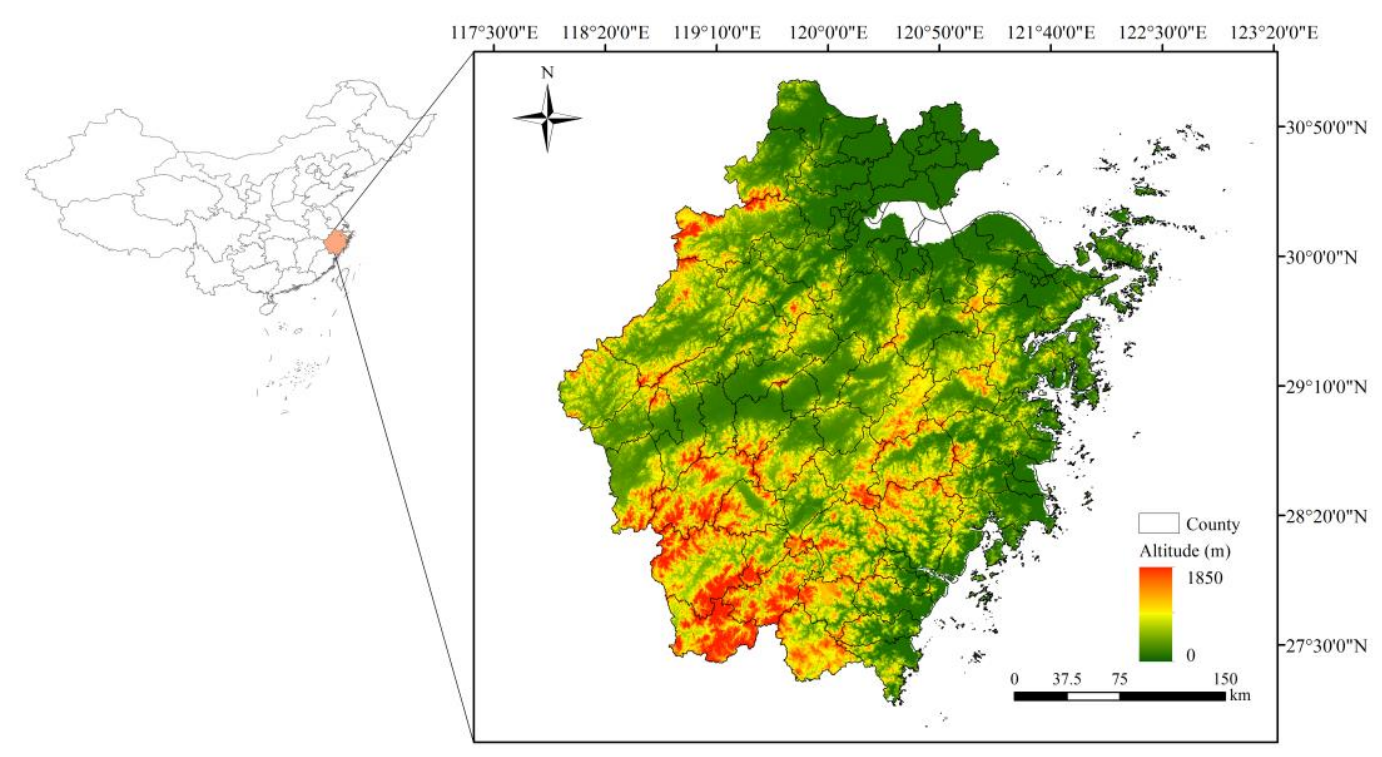

Fig. 1 Location and topography of Zhejiang Province, China.

\subsection{Data source and processing}

Previous studies have shown that human factors affecting agricultural production generally include: the amount of labour, the area of sowing, irrigation, mechanical farming, and the usage of chemical fertilizers, pesticides, electricity, agricultural machinery, plastic film, etc. (Deng et al., 2017; Bai et al., 2018). In this study, we considered the following factors: the personnel engaged in crop farming (Pers), agricultural machinery usage (Mach), fertilizer usage (Fert), plastic mulch usage (Plas), pesticide usage (Pest), and landscape metrics. The data for these variables and the related total yields of agricultural products covered in this study were from 81 counties in Zhejiang Province from 1995 to 2015. The official data were collected from the statistical yearbooks published by government agencies (http://tji.zj.gov.cn/col/col1525563/index.html).

The agricultural land ratio and landscape metrics were calculated from land use maps in 1995, 2005, and 2015 at a spatial resolution of $100 \mathrm{~m} \times 100 \mathrm{~m}$, supplied by the Data Center for Resources and Environmental Sciences (RESDC), Chinese Academy of Sciences (http://www.resdc.cn). Then, five categories of landscapes were generalized throughout the reclassification process (Qiu et al., 2019): agricultural land (cropland, fruit and tea orchards), built-up land (cities, towns, and rural area), forest (broadleaved forests, shrubland, and mixed forests), vacant land (bare land and rocky areas), and water bodies.

\subsection{Measurement of land fragmentation}

Landscape metrics have been widely used to analyse changes in landscape patterns. Four landscape 
metrics were selected in this study to assess fragmentation using Fragstats 4.2 software (McGarigal et al., 2012) (Table 1). Changes in the area of agricultural land directly affect agricultural production. Therefore, agricultural production can be reflected by agricultural land percentages (PLAND) (Lee et al., 2015). In addition, relatively large agricultural land size (mean patch size, MPS), more aggregated distributions (aggregation index, AI) and more regular shapes of the agricultural land (landscape shape index, LSI) increase the efficiency of actual agricultural practice (Deng et al., 2011; Su and Xiao, 2013). When the landscape is fragmented due to human activities, the number of patches increases and the average size of each patch decreases, resulting in more complex edges. Meanwhile, the distribution of agricultural land becomes scattered. By using these indicators, we can evaluate the level of fragmentation in each county and the entire province during the 20 -year research period.

Table 1 Landscape metrics for characterizing agricultural landscape pattern

\begin{tabular}{|c|c|c|c|}
\hline Metrics & Abbreviation & Description & Range \\
\hline Percentage of & PLAND & PLAND equals the percentage of the landscape composed of the & $0<$ PLAND \\
\hline landscape & & corresponding patch type & $\leqslant 100$ \\
\hline Mean patch & MPS & MPS equals the average area of all the agricultural land patches & MPS $>0$ \\
\hline \multicolumn{4}{|l|}{ size } \\
\hline Aggregation & AI & AI equals the number of like adjacencies divided by the maximum & $0 \leqslant \mathrm{AI} \leqslant$ \\
\hline index & & possible number of like adjacencies & 100 \\
\hline Landscape & LSI & LSI equals the total length of the edge divided by the minimum & LSI $\geqslant 1$ \\
\hline shape index & & length of the class edge possible for a maximally aggregated class & \\
\hline
\end{tabular}

Abbreviations: percentage of agricultural landscape (PLAND), mean patch size (MPS), aggregation index (AI), and landscape shape index (LSI).

\subsection{Measurement of production diversification}

For the past two decades, the number of major crop species in Zhejiang has remained stable, but the proportion of different crops in the total output of agricultural products has been constantly changing due to the transformation of crop farming from a single grain crop to diversified agricultural products throughout the country (Su et al., 2014). Simple counting of crop species or formulas based on changes in the number of crop species, such as the Margalef species richness index (Sibhatu et al., 2015), Simpson's index (Ciaian et al., 2018), and the Januszewski index (Looga et al., 2018), failed to accurately 
reflect the trend in the diversification of agricultural production in the study area. Thus, unlike previous studies on production diversity, we believe that using the relative proportion of different crop yields to measure production diversity is more realistic than using the number of crop species at the regional scale. In this study, the production diversity was measured by calculating the agricultural structure coefficient, i.e., the ratio of cash crop output to grain output (CGR) for each county in Zhejiang. This is a simple and unweighted quantitative measure commonly used in China's agricultural economic literature and as an indicator to describe agricultural land use changes and assess planting structure diversity (Ning and Liu, 2013; Li et al., 2018). To test the robustness of this approach, we used Simpson's index to examine whether this influences the results significantly. Simpson's index is often used in the biodiversity literature, and it indicates the cultivated area or yield of different crop species in a region (Huang et al., 2019; Nicod et al., 2019).

The ratio of the cash crop output to grain output can be expressed as follows:

$$
C G R=V_{\text {cashcrop }} / V_{\text {grain }}
$$

where $V_{\text {cashcrop }}$ and $V_{\text {grain }}$ are the output yields of grain and cash crop cultivation, respectively. As the value of CGR increases, the proportion of traditional grain cultivation shrinks, that of cash crop cultivation increases, and agricultural production structure becomes more diverse. Based on the cash crops actually planted in Zhejiang, Eq. (1) can be further expressed as:

$$
C G R=\left(V_{\text {oil }}+V_{\text {vegetable }}+V_{\text {tea }}+V_{\text {fruit }}\right) / V_{\text {grain }}
$$

where $V_{\text {oil }}, V_{\text {vegetable }}, V_{\text {tea }}$, and $V_{\text {fruit }}$ refer to the output yields of oil plants, vegetables, tea, and fruits, respectively. Simpson's index can be expressed as:

$S=1-\sum_{i=1}^{N} V_{i}^{2} /\left(\sum_{i=1}^{N} V_{i}\right)^{2}$

where $y_{i}$ is the output yield of crop $i$ that a county produces, and $N$ is the number of crops. The value of the index varies between zero and one, with a larger value indicating more diversity.

\subsection{Data analysis}

Considering the uncertainty of the effects of LF on agricultural production, we first explored the relationship between agricultural production indicators and landscape metrics using Spearman's correlation analysis. Next, we used landscape metrics together with other control variables in regression models to further investigate the causality of grain crop production (GCP) and APD. 
where $y_{i j}$ denotes the GCP or APD in county $i$ and year $j, \alpha$ is the intercept, $x_{i j}$ denotes the fragmentation metrics in county $i$ and year $j, z_{i j}$ is the control variables in county $i$ and year $j$, and $\beta$ and $\gamma$ are the regression coefficients of $x_{i j}$ and $z_{i j}$, respectively. The residual $\varepsilon_{i j}$ is an unobserved scalar random error. We tested different functional forms of Eq. (3) for normality of the residual (Kolmogorov-Smirnov test) and goodness of fit (R-squared) to select the most appropriate one. Using logarithms for the control variables and for the fragmentation metric of MPS (among other metrics: PLAND and AI lie between 0 and 100 , and LSI is a ratio greater than or equal to 1 , Table 1), we selected the following regression model:

$y_{i j}=\alpha+\beta x_{i j}+\gamma_{1} \ln \left(\right.$ Pers $\left._{i j}\right)+\gamma_{2} \ln \left(\right.$ Mach $\left._{i j}\right)+\gamma_{3} \ln \left(\right.$ Fert $\left._{i j}\right)+\gamma_{4} \ln \left(\right.$ Plas $\left._{i j}\right)+\gamma_{5} \ln \left(\right.$ Pest $\left._{i j}\right)+\varepsilon_{i j}(4)$ where $x_{i j}$ refers to PLAND, $\ln (\mathrm{MPS}), \mathrm{AI}$, and LSI, and $\gamma_{1}, \ldots, \gamma_{5}$ are regression coefficients.

\section{Results}

\subsection{Changes in the agricultural landscape}

The landscape changes in Zhejiang are mainly triggered by urbanization. Due to rapid economic and urban development across the province, the landscape has changed dramatically, mainly transforming from agricultural land to built-up land. Approximately $11.6 \%$ of the agricultural land in Zhejiang was changed to other land use types between 1995 and 2015 (Fig. 2). The agricultural landscape metrics in Zhejiang were summarized as the average values of the counties (or districts) and are shown in Table 2. Nine urban districts with no agricultural land were excluded from the analysis. Due to the loss of agricultural land over the past few decades, PLAND has generally declined in all counties, especially in the more developed northeastern region. Meanwhile, an increasingly fragmented composition and a scattered distribution of agricultural land were observed, as evidenced by the decrease in MPS and AI in Zhejiang during the past two decades. The decline in MPS indicates that the patch size of agricultural land has decreased, while the decline in AI indicates that agricultural lands have become more isolated. The mean LSI of all the counties increased from 1995 to 2015, indicating that the shape of the agricultural land patches became more irregular. 

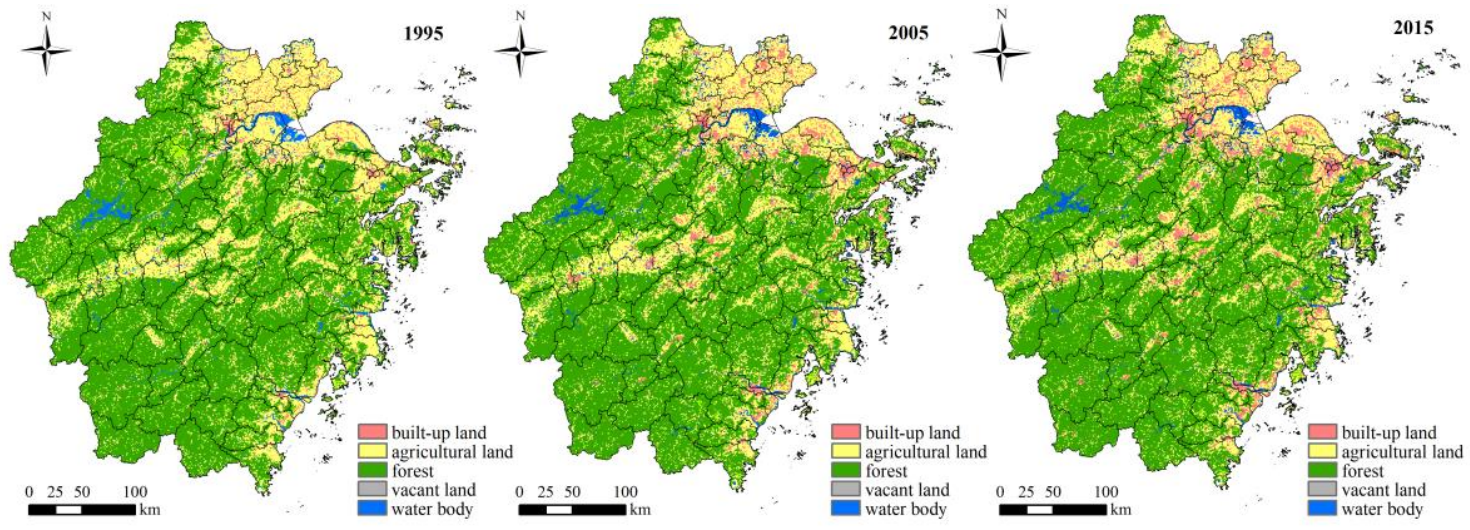

Fig. 2 Landscape patterns in Zhejiang Province, China, between 1995 and 2015.

Table 2 Landscape metrics of the agricultural land in Zhejiang Province, China, between 1995 and

2015.

\begin{tabular}{|c|c|c|c|c|c|c|}
\hline \multirow[t]{2}{*}{ Metrics } & \multicolumn{2}{|l|}{1995} & \multicolumn{2}{|l|}{2005} & \multicolumn{2}{|l|}{2015} \\
\hline & Mean & Range & Mean & Range & Mean & Range \\
\hline PLAND & 35.55 & $2.71-87.63$ & 24.49 & $1.41-63.55$ & 21.76 & $1.23-70.15$ \\
\hline MPS & 24.54 & $0.51-79.85$ & 13.57 & $0.25-53.83$ & 11.86 & $0.08-60.96$ \\
\hline AI & 50.27 & $23.1-97.26$ & 40.41 & $18.93-75.71$ & 38.21 & $19.44-78.74$ \\
\hline LSI & 15.33 & $10.39-20.32$ & 16.72 & $10.8-21.48$ & 18.22 & $10.28-21.28$ \\
\hline
\end{tabular}

Abbreviations: percentage of agricultural landscape (PLAND), mean patch size (MPS), aggregation

214 index (AI), and landscape shape index (LSI).

\subsection{Changes in agricultural production}

The production of cash crops, such as vegetables, tea, and fruits, continuously increased, while the production of grain crops and oil plants decreased between 1995 and 2015 (Table 3). Specifically, fruit production showed a dramatic growth of $244.53 \%$. Vegetable and tea production significantly increased by $89.33 \%$ and $61.54 \%$, respectively. Grain crop production showed a net decrease of $47.99 \%$. This suggested that the agricultural planting structure in Zhejiang Province shifted from traditional grain crop cultivation to more diverse crops, such as vegetables, fruits, and tea. In the past two decades, the value of CGR has grown by $348.60 \%$, indicating that the agricultural production structure has become more diverse. The continued increase in the value of Simpson's index also reflects the diversification trend, demonstrating that using CGR to estimate diversity provides robust results in this study. 
Table 3 Descriptive statistics of the agricultural production variables and agricultural products in

227 Zhejiang Province, China, between 1995 and 2015.

\begin{tabular}{|c|c|c|c|c|c|}
\hline \multirow[t]{2}{*}{ Variables } & \multirow[t]{2}{*}{ Unit } & \multirow[t]{2}{*}{$n$} & \multicolumn{3}{|l|}{ Mean } \\
\hline & & & 1995 & 2005 & 2015 \\
\hline Grain crops & 10000 Tons & 81 & 17.67 & 10.86 & 9.19 \\
\hline Oil plants & 10000 Tons & 81 & 0.62 & 0.60 & 0.47 \\
\hline Vegetables & 10000 Tons & 81 & 11.62 & 21.66 & 22.00 \\
\hline Tea & 10000 Tons & 81 & 0.13 & 0.18 & 0.21 \\
\hline Fruits & 10000 Tons & 81 & 2.65 & 6.58 & 9.13 \\
\hline Personnel engaged in crop farming & 10000 People & 81 & 14.15 & 9.59 & 6.07 \\
\hline Power of agricultural machinery & $10000 \mathrm{kw}$ & 81 & 20.25 & 23.12 & 28.90 \\
\hline Fertilizer & 10000 Tons & 81 & 5.75 & 4.72 & 4.55 \\
\hline Plastic mulch & 10000 Tons & 81 & 0.03 & 0.05 & 0.08 \\
\hline Pesticides & 10000 Tons & 81 & 0.07 & 0.08 & 0.07 \\
\hline CGR & & 81 & 1.07 & 3.43 & 4.80 \\
\hline Simpson's index & & 81 & 0.54 & 0.56 & 0.58 \\
\hline
\end{tabular}

Fig. 3 shows the spatial patterns of grain production and CGR for Zhejiang in 1995, 2005, and 2015. equal to 3; this was the threshold for diversified agricultural production using the Jenks natural breaks classification method (Liu et al., 2019). In 1995, the CGR values of only four scattered counties were greater than 3, while the CGR values of the other counties were generally low, indicating the homogeneity of the province's agricultural production structure. By 2005, the number of counties with CGR values greater than 3 reached 28, most of which were spatially located in the eastern coastal areas. The CGR

235 values of some counties in the western region were significantly improved in the following decade. By 2015, more than half of the counties had a CGR value greater than 3, representing a significant diversification of the agricultural production structure in Zhejiang Province during the past two decades.

238 At the same time, grain production showed a continuous downward trend corresponding to the spatial growth of CGR. 


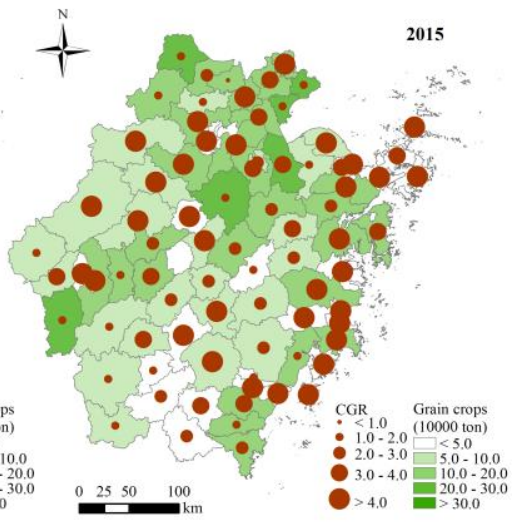

Fig. 3 Distribution of grain production and CGR at the county level in Zhejiang Province, China, between 1995 and 2015.

\subsection{Relationship between land fragmentation and production diversification}

Significant correlations were identified between the landscape metrics and agricultural production indicators (Table 4). Specifically, GCP was positively correlated with PLAND, MPS, and AI but negatively correlated with LSI. The opposite relationship was found between CGR and the landscape metrics. As indicated by the estimation results of the regression models (Table 5), LF had a significant influence on agricultural production. In the regression model with a dependent variable of GCP, the highly significant positive coefficients of $0.02,0.187$, and 0.022 for PLAND, ln (MPS), and AI, respectively, and the highly significant negative coefficient of -0.085 for LSI indicated that high fragmentation was associated with a significant reduction in GCP. In addition, in the regression model with a dependent variable of CGR, the highly significant negative coefficients of $-0.065,-0.52$, and 0.074 for PLAND, ln (MPS), and AI, respectively, and the highly significant positive coefficient of 0.344 for LSI indicated that high fragmentation was associated with a high diversification of agricultural production. These findings demonstrate that LF has a negative impact on GCP but has a significant positive impact on APD.

Table 4 Spearman's correlation analysis between landscape metrics and agricultural production indicators.

\begin{tabular}{lllll}
\hline & PLAND & MPS & AI & LSI \\
\hline GCP & $0.837^{* *}$ & $0.791^{* *}$ & $0.820^{* *}$ & $-0.693^{* *}$ \\
CGR & $-0.417^{* *}$ & $-0.356^{* *}$ & $-0.409^{* *}$ & $0.501^{* *}$ \\
\hline
\end{tabular}

Notes: ${ }^{* *}$ Significant at $1 \%$ and ${ }^{*}$ Significant at $5 \%$. 
Abbreviations: percentage of agricultural landscape (PLAND), mean patch size (MPS), aggregation index (AI), landscape shape index (LSI), grain crop production (GCP), and the ratio of cash crop output to grain output (CGR).

Table 5 Regression results between the landscape metrics and agricultural production by controlling variables

\begin{tabular}{|c|c|c|c|c|c|c|c|}
\hline \multicolumn{2}{|l|}{ Model 1} & \multicolumn{2}{|l|}{ Model 2} & \multicolumn{2}{|l|}{ Model 3} & \multicolumn{2}{|l|}{ Model 4} \\
\hline \multicolumn{8}{|c|}{ Dependent variable: GCP } \\
\hline $\ln$ (Pers) & $0.236^{* *}$ & $\ln$ (Pers) & $0.242^{* *}$ & $\ln$ (Pers) & $0.238^{* *}$ & $\ln$ (Pers) & $0.209^{* *}$ \\
\hline $\ln ($ Mach) & -0.070 & $\ln$ (Mach) & -0.045 & $\ln ($ Mach $)$ & -0.064 & $\ln ($ Mach) & -0.011 \\
\hline $\ln$ (Fert) & $0.465^{* *}$ & $\ln$ (Fert) & $0.518^{* *}$ & $\ln$ (Fert) & $0.470^{* *}$ & $\ln$ (Fert) & $0.533^{* *}$ \\
\hline $\ln$ (Plas) & -0.013 & $\ln$ (Plas) & -0.049 & $\ln$ (Plas) & -0.014 & $\ln$ (Plas) & -0.008 \\
\hline $\ln$ (Pest) & $0.118^{*}$ & $\ln ($ Pest $)$ & $0.146^{*}$ & $\ln ($ Pest $)$ & $0.123^{*}$ & $\ln ($ Pest) & $0.156^{*}$ \\
\hline PLAND & $0.020^{* *}$ & $\ln (\mathrm{MPS})$ & $0.187^{* *}$ & AI & $0.022^{* *}$ & LSI & $-0.085^{* *}$ \\
\hline Constant & $1.063^{* *}$ & Constant & $1.019^{* *}$ & Constant & $0.657^{*}$ & Constant & $2.966^{* *}$ \\
\hline $\mathrm{R}^{2}$ & 0.794 & $\mathrm{R}^{2}$ & 0.761 & $\mathrm{R}^{2}$ & 0.789 & $\mathrm{R}^{2}$ & 0.753 \\
\hline \multicolumn{8}{|c|}{ Dependent variable: CGR } \\
\hline $\ln$ (Pers) & $-0.643^{*}$ & $\ln$ (Pers) & $-0.681^{*}$ & $\ln ($ Pers $)$ & $-0.643^{*}$ & $\ln ($ Pers $)$ & $-0.496^{*}$ \\
\hline $\ln$ (Mach) & $1.205^{* *}$ & $\ln$ (Mach) & $1.099^{* *}$ & $\ln ($ Mach) & $1.200^{* *}$ & $\ln$ (Mach) & $1.038^{* *}$ \\
\hline $\ln$ (Fert) & $-1.118^{* *}$ & $\ln$ (Fert) & $-1.307^{* *}$ & $\ln$ (Fert) & $-1.116^{* *}$ & $\ln$ (Fert) & $-1.305^{* *}$ \\
\hline $\ln$ (Plas) & $0.730^{* *}$ & $\ln$ (Plas) & $0.851^{* *}$ & $\ln$ (Plas) & $0.723^{* *}$ & $\ln$ (Plas) & $0.665^{* *}$ \\
\hline $\ln ($ Pest $)$ & 0.262 & $\ln ($ Pest $)$ & 0.145 & $\ln ($ Pest $)$ & 0.261 & $\ln ($ Pest $)$ & 0.187 \\
\hline PLAND & $-0.065^{* *}$ & $\ln (\mathrm{MPS})$ & $-0.520^{*}$ & AI & $-0.074^{* *}$ & LSI & $0.344^{* *}$ \\
\hline Constant & $7.276^{* *}$ & Constant & $7.325^{* *}$ & Constant & $8.675^{* *}$ & Constant & -0.266 \\
\hline $\mathrm{R}^{2}$ & 0.270 & $\mathrm{R}^{2}$ & 0.233 & $\mathrm{R}^{2}$ & 0.272 & $\mathrm{R}^{2}$ & 0.246 \\
\hline
\end{tabular}

Notes: ${ }^{* *}$ Significant at $1 \%$ and ${ }^{*}$ Significant at $5 \%$.

266 Abbreviations: the personnel engaged in crop farming (Pers), agricultural machinery usage (Mach), 267 fertilizer usage (Fert), plastic mulch usage (Plas), pesticide usage (Pest), percentage of agricultural landscape (PLAND), mean patch size (MPS), aggregation index (AI), landscape shape index (LSI), grain crop production (GCP), and the ratio of cash crop output to grain output (CGR). 


\section{Discussion}

\subsection{The impacts of land fragmentation on agricultural production}

Generally, land fragmentation is considered a major threat to efficient agricultural production systems because, with continued shrinking, fragmented agricultural plots may be hard to cultivate economically. The negative relationship between fragmentation and GCP has been demonstrated throughout the world. Wan and Cheng (2001) reported that the fragmentation of cultivated land is one of the major factors contributing to the decreased benefits of agricultural production in China. Rahman and Rahman (2009) found that land fragmentation had a significant detrimental effect on the productivity and efficiency of rice production in Bangladesh. They estimated that a $1 \%$ increase in land fragmentation reduced rice output by $0.05 \%$ and efficiency by $0.03 \%$. Latruffe and Piet (2014) identified a significant negative impact of land fragmentation on crop yields, leading to increased production costs and reduced revenues and profits of farms in France. Our study in Zhejiang Province confirms the negative aspects of land fragmentation, that is, land fragmentation is a negative factor in food security because it reduces the efficiency of food crop production.

On the other hand, it has been argued that land fragmentation has a positive impact on food security improvement by matching soil types with appropriate food crops (Van Hung et al., 2007; Demetriou et al., 2013), reducing climate hazards and pest risks (Sklenicka and Salek, 2008; Ciaian et al., 2018), and leading to production diversity and dietary diversity (Sikor et al., 2009; Ntihinyurwa et al., 2019). In addition, there is a view that land consolidation practices that reduce fragmentation by relocating and enlarging plots will have a negative impact on agricultural ecosystem services such as biodiversity (Tiemann et al., 2015; Schulte et al., 2017), culture and recreation (Mitchell et al., 2015; Qiu et al., 2019). Our findings support these arguments, as illustrated by the positive relationship between CGR and landscape fragmentation metrics at the provincial level in China. Our findings show that the diversity or heterogeneity of the land and the different soil qualities and production potential caused by fragmentation have effects on the agricultural system. The greater the diversity of growing conditions, the greater the diversity of crops and diets, and the higher the sustainability of food production, the higher the food security. This is consistent with the Sustainable Development Goals from the 2030 Agenda for Sustainable Development of ending hunger, achieving food security, and promoting sustainable agriculture (Goal 1), and sustainable use of land resources and conservation of biodiversity (Goal 15) 

planning and implementation of sustainable and ecological agriculture that needs to be adapted to local conditions, the planting of crops with different adaptability on land with different resource endowments and growing conditions to promote the biodiversity of crops and livestock, an increase in the diversity and characteristics of agricultural products, and the support of sustainable agricultural production (Lee et al., 2015; Fagerholm et al., 2016; Burchfield and Poterie, 2018). This is preferential over marketoriented large-scale industrial agricultural production, which usually leads to a simplification of agricultural production structure, accelerates the loss of agro-biodiversity (Š́lek et al., 2018), reduces comprehensive understanding of regional characteristics, the positioning of agricultural development, land use, and the dual impacts of land fragmentation discussed above.

The reason for the difference between the two above-mentioned viewpoints is that most of the previous studies did not consider the different forms of land fragmentation, the geographical characteristics of different agricultural areas, the transformation of sustainable agriculture, or all the various aspects of food security. Those studies focus only on the impact of land fragmentation on the efficiency of large-scale agricultural production and believe that land fragmentation threatens the total amount of food but ignores food diversity and sustainability, which are important aspects of food security. Therefore, it should be recognized that not all land fragmentation is harmful to agricultural production. The strategy and choices for dealing with land fragmentation should be based on a comprehensive assessment of the local ecological, social, economic, and political contexts and the positioning of agricultural development.

\subsection{Implications for land management}

To alleviate the problem of continuously declining in grain production capacity caused by the loss of cultivated land, since the mid-1990s, the central government of China has implemented a series of policies and measures to protect land resources and promote land consolidation (Yang, 2016). The aim of these policies is to increase cropland area, reduce land fragmentation, mitigate land pollution, and promote agricultural productivity (Song and Pijanowski, 2014; Du et al., 2018). Modern land consolidation projects can usually achieve the goal of reducing the number of scattered plots, regulating 
the shape of plots, and increasing the size of large-scale farms in the context of commercial and mechanized agriculture in China's main grain production bases. However, previous land consolidation management overemphasized the negative impact of fragmentation on productivity and food quantity but ignored the positive impact of fragmentation on food diversity and sustainability. As found in the Zhejiang case study above, it is not necessary to address all the land fragmentation issues in China's rural hilly areas dominated by ecologically sustainable agriculture. Land consolidation should be primarily implemented in more homogenous regions with less variability in elevation, slope, soil quality, and agroecological conditions to achieve the goal of increasing the amount of food. Other regions with greater heterogeneity can maintain a moderate level of fragmentation or develop more local, context-specific land consolidation approaches to take advantage of the positive impacts of fragmentation on production diversity. Since the balance between yield and diversity inevitably involves trade-offs, trade-off analyses, including threshold analysis, multi-objective analysis, scenario analysis, and model simulation, are becoming increasingly necessary (Sherrouse et al., 2017; Yang et al., 2018). Quantifying these trade-offs or synergies improves the management and protection of agricultural land by revealing the optimal allocation of agricultural land services and functions (Deng et al., 2017). The results of these studies will provide scientific support for achieving optimal land fragmentation levels and planning local, specific land consolidation activities.

\subsection{Limitations and future research}

The current research still has some limitations that should be considered in the future. First, more potential influencing factors should be evaluated, including the soil physical, chemical, and biophysical characteristics of agricultural land, natural resources, and regional agricultural policies. In the future, by supplementing and analysing these variables, it should be possible to provide a more complete and comprehensive understanding of the dynamic process of production diversification. Second, it should also be noted that APD does not necessarily mean diversification in the yields of different crops; rather, it can imply the number of crops in a farm or land block or the diversity of the crops. Third, the relationship between land fragmentation and diversification was analysed at the regional landscape scale. These relationships should be further described at the field and farm scales to deepen our knowledge of the decision-making process by farmers related to the diversification of production. Finally, this study has yet to determine the extent and threshold of the impact of land fragmentation on agricultural 
diversification.

\section{Conclusions}

In this paper, we examined agricultural land fragmentation and its implications for production diversification using Zhejiang Province, China, as a case study. Zhejiang represents a typical case for studying land fragmentation and its impacts on agricultural production. The conflicts between the population, land resources and urbanization have made Zhejiang one of the most fragmented agricultural landscapes in China. This paper contributes to the quantitative measurement and presentation of the effects of land fragmentation on production diversification by using landscape metrics and the CGR index. Based on the multi-source data from 1995, 2005 and 2015, we used agricultural labourers, machinery usage, fertilizer usage, plastic mulch usage, pesticide usage, and the landscape metrics of PLAND, MPS, $\mathrm{AI}$, and LSI as the independent variables to explain production diversification. Then, the explicit relationship between fragmentation and diversification was extracted from the results of the model analysis.

The results showed that the agricultural landscape pattern has been increasingly fragmented and agricultural production has been increasingly diverse over the past two decades. We found that land fragmentation was significantly negatively correlated with GCP but was significantly positively correlated with APD. This finding indicated that land fragmentation is an important driver of agricultural diversification at the provincial level in China. We further discussed the positive impact that land fragmentation has on food security improvement from the perspective of food diversity and sustainability. Therefore, the strategies for dealing with land fragmentation should be based on a comprehensive assessment of the local ecological, social, economic, and political contexts and the positioning of agricultural development. The lessons learned from Zhejiang Province will provide scientific support for land consolidation management and agricultural land resource protection.

\section{Conflicts of interest}

The authors declare no conflict of interest.

\section{Acknowledgments}

This research was financially supported by Natural Science Foundation of Zhejiang Province (No. LY19D010002). We gratefully acknowledge the Data Center for Resources and Environmental Sciences, Chinese Academy of Sciences (RESDC) (http://www.resdc.cn) for the supply of source data set. 


\section{References}

Bai, Y., Deng, X., Jiang, S., Zhao, Z., Miao, Y., 2018. Relationship between climate change and lowcarbon agricultural production: A case study in Hebei Province, China. Ecol. Indic. 105, 438-447.

Burchfield, E. K., Poterie, A. T. d. 1., 2018. Determinants of crop diversification in rice-dominated Sri Lankan agricultural systems. J. Rural Stud. 61, 206-215.

Cheng, L., Xia, N., Jiang, P., Zhong, L., Pian, Y., Duan, Y., Huang, Q., Li, M., 2015. Analysis of farmland fragmentation in China Modernization Demonstration Zone since " Reform and Openness": A case study of South Jiangsu Province. Sci. Rep. 5, 11797.

Ciaian, P., Guri, F., Rajcaniova, M., Drabik, D., Paloma, S. G. y., 2018. Land fragmentation and production diversification: A case study from rural Albania. Land Use Pol. 76, 589-599.

Coleman, K., Muhammed, S. E., Milne, A. E., Todman, L. C., Dailey, A. G., Glendining, M. J., Whitmore, A. P., 2017. The landscape model: A model for exploring trade-offs between agricultural production and the environment. Sci. Total Environ. 609(Supplement C), 1483-1499.

Costanza, R., de Groot, R., Braat, L., Kubiszewski, I., Fioramonti, L., Sutton, P., Farber, S., Grasso, M., 2017. Twenty years of ecosystem services: How far have we come and how far do we still need to go? Ecosyst. Serv. 28, 1-16.

Demetriou, D., Stillwell, J., See, L., 2013. A new methodology for measuring land fragmentation. Comput. Environ. Urban Syst. 39, 71-80.

Deng, J. S., Qiu, L. F., Wang, K., Yang, H., Shi, Y. Y., 2011. An integrated analysis of urbanizationtriggered cropland loss trajectory and implications for sustainable land management. Cities 28(2), $127-137$.

Deng, X., Gibson, J., Wang, P., 2017. Management of trade-offs between cultivated land conversions and land productivity in Shandong Province. J. Clean Prod. 142, 767-774.

Deng, X., Gibson, J., Wang, P., 2017. Relationship between landscape diversity and crop production: a case study in the Hebei Province of China based on multi-source data integration. J. Clean Prod. $142,985-992$.

Du, X., Zhang, X., Jin, X., 2018. Assessing the effectiveness of land consolidation for improving agricultural productivity in China. Land Use Pol. 70, 360-367.

Fagerholm, N., Oteros-Rozas, E., Raymond, C. M., Torralba, M., Moreno, G., Plieninger, T., 2016. 
Assessing linkages between ecosystem services, land-use and well-being in an agroforestry landscape using public participation GIS. Appl. Geogr. 74, 30-46.

Huang, C., Zhou, Z., Peng, C., Teng, M., Wang, P., 2019. How is biodiversity changing in response to ecological restoration in terrestrial ecosystems? A meta-analysis in China. Sci. Total Environ. 650, $1-9$.

Inter-Agency and Expert Group on SDG Indicators, 2017. Global indicator framework for the Sustainable Development Goals and targets of the 2030 Agenda for Sustainable Development. the United Nations Statistical Commission, New York.

Jia, L., Petrick, M., 2014. How does land fragmentation affect off-farm labor supply: panel data evidence from China. Agric. Econ. 45(3), 369-380.

Kawasaki, K., 2010. The costs and benefits of land fragmentation of rice farms in Japan. Aust. J. Agr. Resour. Econ. 54(4), 509-526.

Lai, L., Huang, X., Yang, H., Chuai, X., Zhang, M., Zhong, T., Chen, Z., Chen, Y., Wang, X., Thompson, J. R., 2016. Carbon emissions from land-use change and management in China between 1990 and 2010. Sci. Adv. 2(11), e1601063.

Latruffe, L., Piet, L., 2014. Does land fragmentation affect farm performance? A case study from Brittany, France. Agric. Syst. 129, 68-80.

Lee, Y.-C., Ahern, J., Yeh, C.-T., 2015. Ecosystem services in peri-urban landscapes: The effects of agricultural landscape change on ecosystem services in Taiwan's western coastal plain. Landsc. Urban Plan. 139, 137-148.

Lee, Y. C., Huang, S. L., 2018. Spatial emergy analysis of agricultural landscape change: Does fragmentation matter? Ecol. Indic. 93, 975-985.

Li, E., Xu, Y., Yong, Y., Wei, L., 2018. Agricultural structure adjustment and rural transformation development in China, Progress in Geography 37(05), 698-709.

Li, H., Yang, Z., Dai, M., Diao, X., Dai, S., Fang, T., Dong, X., 2020. Input of Cd from agriculture phosphate fertilizer application in China during 2006-2016. Sci. Total Environ. 698, 134149.

Liu, Y., Huang, X., Yang, H., Zhong, T., 2014. Environmental effects of land-use/cover change caused by urbanization and policies in Southwest China Karst area - A case study of Guiyang. Habitat Int. 44, 339-348. 
Liu, Y., Li, T., Zhao, W., Wang, S., Fu, B., 2019. Landscape functional zoning at a county level based on ecosystem services bundle: Methods comparison and management indication. J. Environ. Manage. $249,109315$.

Liu, Y., Sun, D., Wang, H., Wang, X., Yu, G., Zhao, X., 2020. An evaluation of China's agricultural green production: 1978-2017. J. Clean Prod. 243, 118483.

Loison, S. A., 2015. Rural Livelihood Diversification in Sub-Saharan Africa: A Literature Review AU Alobo Loison, Sarah. J. Dev. Stud. 51(9), 1125-1138.

Looga, J., Jürgenson, E., Sikk, K., Matveev, E., Maasikamäe, S., 2018. Land fragmentation and other determinants of agricultural farm productivity: The case of Estonia. Land Use Pol. 79, 285-292.

Lu, H., Xie, H., He, Y., Wu, Z., Zhang, X., 2018. Assessing the impacts of land fragmentation and plot size on yields and costs: A translog production model and cost function approach. Agric. Syst. 161, $81-88$

Lu, H., Xie, H., Yao, G., 2019. Impact of land fragmentation on marginal productivity of agricultural labor and non-agricultural labor supply: A case study of Jiangsu, China. Habitat Int. 83, 65-72.

Makate, C., Wang, R., Makate, M., Mango, N., 2016. Crop diversification and livelihoods of smallholder farmers in Zimbabwe: adaptive management for environmental change. SpringerPlus 5(1), 11351135.

McCord, P. F., Cox, M., Schmitt-Harsh, M., Evans, T., 2015. Crop diversification as a smallholder livelihood strategy within semi-arid agricultural systems near Mount Kenya. Land Use Pol. 42, 738750.

McGarigal, K., Cushman, S. A., Ene, E., 2012. FRAGSTATS v4: Spatial Pattern Analysis Program for Categorical and Continuous Maps. the University of Massachusetts, Amherst.

Mekki, I., Bailly, J. S., Jacob, F., Chebbi, H., Ajmi, T., Blanca, Y., Zairi, A., Biarnès, A., 2018. Impact of farmland fragmentation on rainfed crop allocation in Mediterranean landscapes: A case study of the Lebna watershed in Cap Bon, Tunisia. Land Use Pol. 75, 772-783.

Mitchell, M.G.E., Suarez-Castro, A.F., Martinez-Harms, M., Maron, M., McAlpine, C., Gaston, K.J., Johansen, K., Rhodes, J.R., 2015. Reframing landscape fragmentation's effects on ecosystem services. Trends Ecol. Evol. 30(4), 190-198.

Nicod, C., Leys, B., Ferrez, Y., Manneville, V., Mouly, A., Greffier, B., Hennequin, C., Bouton, Y., 
Prévost-Bouré, N.C., Gillet, F., 2019. Towards the assessment of biodiversity and management practices in mountain pastures using diagnostic species? Ecol. Indic. 107, 105584.

Ning, A., Liu, Y., 2013. The efficiency of agricultural grain production under urbanization. Resources Science 35(6), 1174-1183.

Ntihinyurwa, P. D., de Vries, W. T., Chigbu, U. E., Dukwiyimpuhwe, P. A., 2019. The positive impacts of farm land fragmentation in Rwanda. Land Use Pol. 81, 565-581.

Qiu, L., Pan, Y., Zhu, J., Amable, G. S., Xu, B., 2019. Integrated analysis of urbanization-triggered land use change trajectory and implications for ecological land management: A case study in Fuyang, China. Sci. Total Environ. 660, 209-217.

Rahman, S., Rahman, M., 2009. Impact of land fragmentation and resource ownership on productivity and efficiency: The case of rice producers in Bangladesh. Land Use Pol. 26(1), 95-103.

Rosa, I. M. D., Gabriel, C., Carreiras, J. M. B., 2017. Spatial and temporal dimensions of landscape fragmentation across the Brazilian Amazon. Reg. Envir. Chang. 17(6), 1687-1699.

Šálek, M., Hula, V., Kipson, M., Daňková, R., Niedobová, J., Gamero, A., 2018. Bringing diversity back to agriculture: Smaller fields and non-crop elements enhance biodiversity in intensively managed arable farmlands. Ecol. Indic. 90, 65-73.

Schulte, L. A., Niemi, J., Helmers, M. J., Liebman, M., Arbuckle, J. G., James, D. E., Kolka, R. K., O’Neal, M. E., Tomer, M. D., Tyndall, J. C., Asbjornsen, H., Drobney, P., Neal, J., Van Ryswyk, G., Witte, C., 2017. Prairie strips improve biodiversity and the delivery of multiple ecosystem services from corn-soybean croplands. Proc. Natl. Acad. Sci. U. S. A. 114(42), 11247-11252.

Sherrouse, B.C., Semmens, D.J., Ancona, Z.H., Brunner, N.M., 2017. Analyzing land-use change scenarios for trade-offs among cultural ecosystem services in the Southern Rocky Mountains. Ecosyst. Serv. 26(Part B), 431-444.

Sibhatu, K. T., Krishna, V. V., Qaim, M., 2015. Production diversity and dietary diversity in smallholder farm households. Proc. Natl. Acad. Sci. U. S. A. 112(34), 10657-10662.

Sichoongwe, K., Mapemba, L., Tembo, G., Ng'ong'ola, D., 2014. The Determinants and Extent of Crop Diversification Among Smallholder Farmers: A Case Study of Southern Province Zambia. MaSSP Working Paper, Washington, D.C.

Sikor, T., Müller, D., Stahl, J., 2009. Land Fragmentation and Cropland Abandonment in Albania: 
Implications for the Roles of State and Community in Post-Socialist Land Consolidation. World Dev. 37(8), 1411-1423.

Sklenicka, P., Salek, M., 2008. Ownership and soil quality as sources of agricultural land fragmentation in highly fragmented ownership patterns. Landsc. Ecol. 23(3), 299-311.

Song, W., Pijanowski, B. C., 2014. The effects of China's cultivated land balance program on potential land productivity at a national scale. Appl. Geogr. 46, 158-170.

Su, S., Xiao, R., 2013. Spatially varying determinants of farmland conversion across Qiantang watershed, China. Environ. Manage. 52(4), 907-916.

Su, S., Xiao, R., Zhang, Y., 2012. Multi-scale analysis of spatially varying relationships between agricultural landscape patterns and urbanization using geographically weighted regression. Appl. Geogr. 32(2), 360-375.

Su, S., Yang, C., Hu, Y., Luo, F., Wang, Y., 2014. Progressive landscape fragmentation in relation to cash crop cultivation. Appl. Geogr. 53, 20-31.

Tan, S., Heerink, N., Kruseman, G., Qu, F., 2008. Do fragmented landholdings have higher production costs? Evidence from rice farmers in Northeastern Jiangxi province, P.R. China. China Econ. Rev. 19(3), 347-358.

Tan, S., Heerink, N., Kuyvenhoven, A., Qu, F., 2010. Impact of land fragmentation on rice producers' technical efficiency in South-East China. NJAS-Wagen. J. Life Sci. 57(2), 117-123.

The People's Government of Zhejiang Province, 2019. General Introduction of Zhejiang Province. http://www.zj.gov.cn/col/col1568516/index.html.

Tiemann, L. K., Grandy, A. S., Atkinson, E. E., Marin-Spiotta, E., McDaniel, M. D., 2015. Crop rotational diversity enhances belowground communities and functions in an agroecosystem. Ecol. Lett. 18(8), $761-771$.

Van Hung, P., MacAulay, T.G., Marsh, S.P., 2007. The economics of land fragmentation in the north of Vietnam. Aust. J. Agr. Resour. Econ. 51(2), 195-211.

Walz, U., Syrbe, R.-U., 2018. Landscape indicators - Monitoring of biodiversity and ecosystem services at landscape level. Ecol. Indic. 94(2), 1-5.

Wan, G. H., Cheng, E., 2001. Effects of land fragmentation and returns to scale in the Chinese farming sector. Appl. Econ. 33(2), 183-194. 
World Bank, 2016. World Development Indicators. https://data.worldbank.org/indicator/AG.LND.

$$
\text { ARBL.HA.PC }
$$

Yang, H., 2014. China must continue the momentum of green law. Nature 509(7502), 535.

Yang, H., 2016. China's soil plan needs strong support. Nature 536(7617), 375.

Yang, W., Jin, Y., Sun, T., Yang, Z., Cai, Y., Yi, Y., 2018. Trade-offs among ecosystem services in coastal wetlands under the effects of reclamation activities. Ecol. Indic. 92, 354-366.

You, H., 2017. Agricultural landscape dynamics in response to economic transition: Comparisons between different spatial planning zones in Ningbo region, China. Land Use Pol. 61, 316-328.

Zhang, L., Huang, J., Rozelle, S., 1997. Land policy and land use in China. Agricultural Polices in China, Organization for Economic Co-operation and Development, Paris, 71-77.

Zhao, T., Zhao, Y., Li, M., 2019. Landscape Performance for Coordinated Development of Rural Communities \& Small-Towns Based on “Ecological Priority and All-Area Integrated Development”: Six Case Studies in East China's Zhejiang Province. Sustainability 11(15), 4096.

Zhejiang Agricultural Department, 2016. The 13th Five-Year Plan for the Development of Modern Ecological Cycle Agriculture in Zhejiang Province. Zhejiang Agricultural Department, Hangzhou. http://www.zj.gov.cn/art/2016/8/15/art_5495_2181201.html 